This item was submitted to Loughborough's Research Repository by the author.

Items in Figshare are protected by copyright, with all rights reserved, unless otherwise indicated.

\title{
Relationship between antidepressant therapy and risk for cardiovascular events in patients with and without cardiovascular disease
}

\section{PLEASE CITE THE PUBLISHED VERSION}

http://dx.doi.org/10.1037/hea0000602

\section{PUBLISHER}

(c) American Psychological Association

\section{VERSION}

AM (Accepted Manuscript)

\section{PUBLISHER STATEMENT}

This work is made available according to the conditions of the Creative Commons Attribution-NonCommercialNoDerivatives 4.0 International (CC BY-NC-ND 4.0) licence. Full details of this licence are available at: https://creativecommons.org/licenses/by-nc-nd/4.0/

\section{LICENCE}

CC BY-NC-ND 4.0

\section{REPOSITORY RECORD}

Lavoie, Kim L., Nicola J. Paine, Roxanne Pelletier, Andre Arsenault, Jean G. Diodati, Tavis S. Campbell, Louise Pilote, and Simon L. Bacon. 2019. "Relationship Between Antidepressant Therapy and Risk for Cardiovascular Events in Patients with and Without Cardiovascular Disease”. figshare.

https://hdl.handle.net/2134/27783. 
Relationship between antidepressant therapy and risk for cardiovascular events in patients with and without cardiovascular disease

Kim L. Lavoie, PhD ${ }^{\mathrm{a}, \mathrm{b}}$, Nicola J. Paine, $\mathrm{PhD}^{\mathrm{b}, \mathrm{c}, \mathrm{d}}$, Roxanne Pelletier, $\mathrm{PhD}^{\mathrm{b}}$, André Arsenault, $M^{b}$, Jean G. Diodati, $\mathrm{MD}^{\mathrm{b}}$, Tavis S. Campbell, $\mathrm{PhD}^{\mathrm{e}}$, Louise Pilote, MD, PhD, MPH ${ }^{\mathrm{f}, \mathrm{g}, \mathrm{h}}$ and Simon L. Bacon, $\mathrm{PhD}^{\mathrm{b}, \mathrm{d}}$.

a Department of Psychology, University of Québec at Montréal (UQAM), Montréal, Canada; ${ }^{\text {b }}$ Montreal Behavioural Medicine Centre, Research Center, Centre intégrée universitaire de services de sante et sociaux - Nord de l'lle, Hôpital du Sacré-Cœur de Montréal, Montréal, Canada; ' School of Sport, Exercise and Health Science, Loughborough University, Loughborough, United Kingdom; ' Department of Exercise Science, Concordia University, Montreal, Canada; ${ }^{e}$ Department of Psychology, University of Calgary, Calgary, Canada; ${ }^{\dagger}$ Division of Clinical Epidemiology, McGill University Health Centre, Montréal, Canada; ${ }^{9}$ The Research Institute of the McGill University Health Centre, Montreal, Canada; ${ }^{\text {h Division of }}$ General Internal Medicine, Department of Medicine, McGill University Montreal, Canada

Corresponding author: Kim L. Lavoie, PhD, Montreal Behavioural Medicine Centre, Research Center, Centre intégrée universitaire de services de santé et sociaux - Nord de l'lle, Hôpital du Sacré-Cœur de Montréal, Montréal, Canada. Phone: +1-514-338-2222 ext.3709, Fax: +1-514987-7953; e-mail: kim.lavoie@mbmc-cmcm.ca

Word count: 3872 (text); 249 (abstract)

Running head: Antidepressant treatment and cardiovascular outcomes 


\section{Abstract}

Objective: The American Heart Association has endorsed depression as a cardiac risk factor and recommends screening as part of routine practice. This has been met with controversy due to inconsistencies in the data linking depression treatment to better cardiovascular outcomes. Our objective was to prospectively assess the association between depression treatment (defined as being prescribed antidepressant medication) and major adverse cardiovascular events (MACE) in patients referred for exercise stress tests.

Methods: 2385 consecutive patients presenting for myocardial perfusion exercise stress tests underwent a sociodemographic, medical, and psychiatric interview (PRIME-MD) and completed the Beck Depression Inventory (BDI). History of CVD and antidepressant use was self-reported and verified via chart review. Participants followed over an 8.8 year follow-up, and information regarding MACE incidence (including cardiac mortality, non-fatal myocardial infarction, revascularization procedures, cerebrovascular events) was obtained from provincial administrative databases.

Results: $8 \%(n=190)$ of the sample were taking antidepressants at baseline, $41 \%(n=916)$ had a history of CVD, and $38.7 \%(n=921)$ had depression according to the PRIME-MD or BDI. Antidepressant treatment was associated with a $30 \%$ reduced risk of MACE (HR=0.697; $95 \% \mathrm{Cl}=0.504-0.964 ; \mathrm{p}=.029) . \mathrm{A} 46 \%$ reduction in risk was associated with antidepressant treatment among those without CVD (HR=0.542; 95\%Cl=0.299-0.981; $\mathrm{p}=.043)$. In depressed patients, a 33\% reduction in risk of MACE associated with antidepressant use was seen (adjusted $\mathrm{HR}=0.674 ; 95 \% \mathrm{Cl}=0.440-1.033 ; \mathrm{p}=.07$ ).

Conclusions: Antidepressants may be cardio-protective among patients presenting for stress testing independent of risk factors including CVD and depression. Results support treating depression with antidepressants in this population to reduce risk of MACE. 
Key words: Antidepressant treatment, Depression, cardiovascular disease, major adverse cardiovascular events 


\section{Introduction}

Multiple studies have documented a disproportionately high rate of depressive symptomatology and clinical depression (i.e., major depressive disorder, MDD) among individuals with or at elevated risk for cardiovascular disease (CVD) (Barefoot et al., 2000; Carney et al., 1987; Frasure-Smith, Lesperance, \& Talajic, 1993; Frasure-Smith, Lesperance, \& Talajic, 1995b; Lane, Carroll, Ring, Beevers, \& Lip, 2002; Steeds, Bickerton, Smith, \& Muthusamy, 2004). Several reports have also linked depression to worse cardiovascular outcomes in both healthy and established populations, including an increased risk of major cardiovascular events, allcause mortality, and poorer quality of life (Anda et al., 1993; Ariyo et al., 2000; Barefoot et al., 1996; Blumenthal et al., 2003; Burg, Benedetto, \& Soufer, 2003; Frasure-Smith \& Lesperance, 2005)

The amount and robustness of this data has recently lead the American Heart Association (AHA) to endorse depression as a cardiac risk factor, and now recommends depression screening as part of routine practice (Lichtman et al., 2014). Despite the compelling nature of this recommendation, it has been met with controversy due to a paucity of data linking depression treatment, including psychological and pharmacological-based treatments (Joynt \& O'Connor, 2005) to better cardiovascular outcomes (Thombs et al., 2008; Thombs et al., 2013). Indeed, while there is evidence that depression screening can identify those at risk for worse cardiovascular outcomes (Elderon, Smolderen, Na, \& Whooley, 2011), few studies have actually linked depression treatment to improved cardiovascular outcomes (Taylor et al., 2005). Further, among those that have, (Davidson et al., 2013; Katon et al., 2010) they did not assessed the role of antidepressants.

In this study, we prospectively assessed the association between depression treatment (defined as being prescribed antidepressant medication at baseline) and the occurrence of major adverse cardiovascular events (MACE) over an average of 8.8 years in patients undergoing 
myocardial perfusion exercise stress tests, both in the entire sample and in those with and without evidence of CVD at baseline. As a secondary analysis, we also assessed the impact of antidepressant treatment in the subgroup of patients who had depression at baseline.

\section{Methods}

\section{Participants}

This is a sub-analysis of the Depression Effects on Coronary Artery Disease Events (DECADE) prospective observational Study, so the methods have been described elsewhere (Paine, Bacon, et al., 2016; Pelletier et al., 2015). Briefly, the sample included 2460 consecutive patients who presented to the Montreal Heart Institute $(\mathrm{MHI})$ for diagnostic myocardial perfusion single photon emission computed tomography (SPECT) exercise stress testing between September 1998 and June 2002. All patients who were presenting for nuclear exercise stress tests who met inclusion criteria, were approached to participate, meaning our sample was not a randomly selected or a convenience sample. However, some patients were occasionally "missed" due to staffing limitations, likely at a rate estimated to be less than $5 \%$, but this would have occurred at random. Patients were eligible if they were between the ages of 18 and 75, medically stable, and were fluent in English or French. Patients were excluded if they had a documented medical condition that conferred greater risk of illness morbidity than CVD (e.g., cancer); if they were inpatients at the time of their stress test; or if they were medically unstable (e.g., major cardiac event in the last 4 weeks). This protocol was approved by the MHI's ethics review board (ID: 07-965) and participants provided written, informed consent.

\section{Study Procedure}

Patients were approached after completing their exercise stress test. Patients underwent a medical history interview that included providing information about medications, followed by a structured psychiatric interview (PRIME-MD) (Spitzer et al., 1994), and completed the Beck 
Depression Inventory (BDI). All medical diagnoses, procedures and events occurring during the period between recruitment and December $31^{\text {st }} 2008$ were obtained from Quebec's healthcare administrative databases (RAMQ and Medecho) which record all billable acts, visits and interventions in the province of Quebec. Official mortality data over the same period was obtained from the Institut de la statistique du Québec (ISQ), which records date of death and primary and secondary causes.

\section{Baseline assessments}

All participants underwent SPECT myocardial perfusion exercise stress testing (treadmill, Bruce protocol) according to standard procedures (Anagnostopoulos et al., 2004). Ischemia diagnoses were made by experienced Nuclear Medicine Physicians. Data regarding socio-demographics, health behaviors, clinical risk factors, history of CVD and medications were self-reported and verified via interview. History of CVD was defined as having had a previous MI, percutaneous coronary intervention $(\mathrm{PCl})$, coronary artery bypass graft (CABG), or stroke.

\section{Depression measures:}

Depression was determined by assessing the presence of a depressive disorder (i.e., clinical depression) or the presence of clinically significant depressive symptoms. Depressive disorders (including major and minor depression, dysthymia, and bipolar disorder) were assessed at baseline using the Primary Care Evaluation of Mental Disorders (PRIME-MD)(Spitzer et al., 1994). This instrument was also used to assess the anxiety disorders (panic disorder, generalized anxiety disorder, 'other' anxiety disorder) for descriptive and adjustment purposes. The PRIME-MD is a brief, semi-structured psychiatric interview that was developed to identify the most common DSM-IV disorders seen in primary and tertiary care settings. Validation studies have reported a specificity of $88 \%$, a sensitivity of $83 \%$, and a kappa of .71 for the mood disorder module, which is comparable to longer interviews such as the Structured Clinical 
Interview for DSM-IV (Spitzer, Kroenke, \& Williams, 1999; Spitzer et al., 1994). An electronic version of the interview was administered by an experienced PhD-level psychology student and/or licensed clinical psychologist.

Depressive symptomatology was measured using the Beck Depression Inventory (BDI) (Beck \& Steer, 1987; Beck, Steer, \& Garbin, 1988), which is a 21 -item self-report questionnaire that is one of the most commonly used instruments in studies assessing depression in CAD patients. It has excellent internal consistency $(\alpha=.90-.91)$ and high construct validity $(r=.89)$ (Beck et al., 1988). BDI scores $\geq 10$ are considered clinically significant (denoting mild depression (Moullec, Plourde, Lavoie, \& Bacon, 2015)) and have been shown to be predictive of worse cardiovascular outcomes (Lesperance, Frasure-Smith, Talajic, \& Bourassa, 2002). A patient was classified as having depression if they met criteria for one or more mood disorders according to the PRIME-MD (which uses a diagnostic algorithm based on DSM-IV criteria) or had a score on the BDI $\geq 10$, which has been shown to be clinically significant (Frasure-Smith, Lesperance, Juneau, Talajic, \& Bourassa, 1999; Frasure-Smith, Lesperance, \& Talajic, 1995a).

\section{Follow-up outcome assessment}

MACE was categorized according to the standard protocol published by the WHO (Luepker, Evans, McKeigue, \& Reddy, 2004) and included: cardiac mortality, non-fatal MI, revascularization procedures, and cerebrovascular events. Cause of death was coded according to the ICD system. The primary reported cause of death was used to define cause of mortality. All International Classification of Disease (ICD)-9 (before April $1^{\text {st }} 2006$ ), ICD-10 (beginning April $1^{\text {st }}$ 2006), Manuel des médecins omnipraticiens et spécialistes (for intervention procedures), and ISQ cause of death coding classifications used in the study have been previously reported (Pelletier et al., 2015).

\section{Data reduction and statistical analyses}


All data were analyzed using SAS Version 9.3 (SAS Institute, Cary, North Carolina, USA). Of the 2460 participants recruited, 75 were lost to follow-up due to missing data in the matching process (such as the absence of birth date) with the RAMQ databases, resulting in a final sample of 2385 patients. Rubin's rules (Rubin, 1987) were followed for our missing data analysis procedures, using multiple imputation (Barzi \& Woodward, 2004) with missing at random (MAR) assumptions. Using the PROC MI method of multiple multivariate imputation in SAS, we independently analyzed 20 copies of the data. PROC MIANALYZE was used according to Harrell's guidelines (Harrell, 2001). One-way general linear models and $\mathrm{X}^{2}$ analyses were used to compare baseline sociodemographic and clinical characteristics.

Cox regression models were used to assess the main effect of antidepressant use on time to first MACE. The first occurrence of the outcome variable was taken as the event for analysis. Owing to the known association of the following variables with CVD outcomes (Rosengren et al., 2004), regression models were adjusted for the following a-priori defined covariates: baseline age, sex, smoking status, BMI, history of CVD (except for CVD stratified analyses), diabetes, hypertension, dyslipidemia, SPECT evidence of exercise-induced myocardial ischemia (on index stress test), baseline anxiety disorder (PRIME-MD), and baseline depression (except for depressed subgroup analyses).

\section{Results}

\section{Sample characteristics}

Sample characteristics are presented in Table 1. Briefly, the sample was $67 \%$ male, nearly $99 \%$ white, with a mean age of $56.8[ \pm 8.5]$ years. A total of $41 \%$ had a history of CVD, $41 \%$ had ischemia on the index stress test, and $30 \%$ experienced a MACE during the follow-up (mean time to $\mathrm{MACE}=6.8[ \pm 3.09]$ years $)$. Out of the total sample of 2385 patients, only $8 \%(\mathrm{~N}=190)$ 
were taking antidepressants at baseline, the majority of which (70\%) were selective serotonin reuptake inhibitors (SSRl's). A total of $38.7 \%(n=921)$ of the sample had depression characterised by the presence of a depressive disorder (PRIME-MD) or a BDI score $\geq 10$. In the patients who were identified as depressed $(\mathrm{N}=921)$, only $12.6 \%(\mathrm{~N}=116)$ were taking antidepressants. Only $14 \%(\mathrm{~N}=329)$ of our sample had major depression (per diagnosis/classification using the PRIME-MD), however out of those who were taking antidepressants $(\mathrm{N}=190)$ nearly $30 \%$ of those individuals had major depression. In the patients who were identified as having an anxiety disorder $(n=475), 75$ patients were taking an antidepressant, but only 11 patients with anxiety disorders only (i.e., no cormorbid depression) were taking antidepressants.

Sample characteristics presented as a function of antidepressant treatment at baseline are also presented in Table 1. Group differences were evident for certain characteristics: patients taking antidepressants were younger and less likely to be male. Conversely, in patients not taking antidepressants, there were significantly higher rates of cohabitating, current smokers, hyperlipidemia, beta-blocker use, aspirin use, and significantly higher resting systolic and diastolic blood pressure ( $p$ 's <.05). Across the whole sample, rates of depressive and anxiety disorders were also higher in patients not taking antidepressants, but BDI score was higher in patients taking antidepressants ( $p$ 's <.001).

\section{Association between antidepressant use and risk of MACE in the whole sample}

Unadjusted analyses examining the association between antidepressant use and MACE revealed a significant reduction in risk of $35 \%$ of $\mathrm{MACE}(\mathrm{HR}=0.651 ; 95 \% \mathrm{Cl}=0.474-0.896 ; p=$ .008). After adjustment for covariates including baseline depression, the use of antidepressants 
was still associated with a significant $30 \%$ reduced risk of MACE over the follow-up (adjusted $\mathrm{HR}=0.697 ; 95 \% \mathrm{Cl}=0.504-0.964 ; p=.029)$ (see Table 2 , figure 1 ).

Association between antidepressant use and risk of MACE in patients with vs. without CVD

There were also differences in MACE risk associated with antidepressant use as a function of CVD status in stratified analyses (see Table 3). In unadjusted analyses, patients without CVD had a $39.5 \%$ reduced risk of MACE that was marginally significant $(\mathrm{HR}=0.605 ; 95 \% \mathrm{Cl}=0.364$ $-1.008 ; p=.054)$. Though risk estimates were in the same direction, there was no significant reduction in risk of MACE observed among those with CVD $(\mathrm{HR}=0.715 ; 95 \% \mathrm{Cl}=0.461-$ 1.110; $p=.135)$. After adjustment for covariates, the reduced risk of MACE associated with antidepressant use among patients without CVD was significant and increased to $46 \%$ (adjusted $\mathrm{HR}=0.542 ; 95 \% \mathrm{Cl}=0.299-0.981 ; p=.043)$; however, the risk of MACE associated with antidepressant use among those with CVD did not reach significance after covariate adjustment (adjusted $\mathrm{HR}=0.690 ; 95 \% \mathrm{Cl}=0.437-1.091 ; p=.113$ ) (see figure 2 ).

\section{Association between antidepressant use and risk of MACE in depressed patients}

Among patients identified as depressed at baseline, only $12.6 \%(n=116)$ were taking antidepressants. In secondary subgroup analyses among depressed patients, results revealed a significant $37 \%$ reduction in risk of MACE associated with antidepressant use $(H R=0.629$; $95 \% \mathrm{Cl}=0.414-0.957 ; \mathrm{p}=0.030)$. Though risk estimates were in the same direction, this became a non-significant trend after covariate adjustment (adjusted $\mathrm{HR}=0.674 ; 95 \% \mathrm{Cl}=0.440-1.033$; p=.07) (see Table 4). 


\section{Sensitivity analyses}

Supplementary analyses adjusting for depression using different definitions (i.e., major depression/minor depression and continuous BDI scores) revealed a similar pattern of results (data not shown). Additionally, supplementary analyses excluding anxiety disorders as a covariate (due to potential multicollinearity with depression) also revealed a similar pattern of results (data not shown). Finally, we conducted a sensitivity analysis including the four non apriori defined covariates that were found to be significantly different between those taking and not taking anti-depressants at baseline (i.e., cohabitation and use of beta-blockers, lipid lowering medication, and aspirin), both in the whole sample and in those identified as depressed at baseline. These analyses also revealed a similar pattern of results, which can be found in supplementary content (Tables S1 and S2).

\section{Discussion}

We prospectively assessed the association between antidepressant depression treatment (defined as being prescribed antidepressant medication, primarily SSRI's) and occurrence of MACE in patients with and without CVD undergoing SPECT exercise stress tests, over an average 8.8 year follow up period. We observed a $30 \%$ reduction in 8 -year risk of MACE among patients prescribed antidepressants after adjusting for several important covariates including age, sex, traditional risk factors, CVD history, and the presence of baseline anxiety and depressive disorders. This indicates that among patients with or at risk for CVD, antidepressants may be cardio-protective, irrespective of baseline depression status. Additionally, in stratified analyses, we observed a $46 \%$ reduction in risk associated with antidepressant use among those without CVD at baseline that was not observed among patients with a history of CVD. This suggests that the cardio-protective effects of antidepressant 
treatment may be even stronger among patients early in the disease process, before the occurrence of any major cardiac events. Finally, we found a $37 \%$ reduced risk of MACE associated with antidepressant use in the subgroup of patients identified as depressed according to the PRIME-MD or BDI at baseline, which became a trend after full covariate adjustment. Given that risk estimates among depressed patients were consistent with those for entire sample suggests that this may have been due to reduced power given a lower sample size in subgroup analyses. Indeed, only $12.6 \%(n=116)$ of patients identified as depressed at baseline were taking antidepressants. This is noteworthy considering our definition of definition includes those who met diagnostic criteria for a depressive disorder according to the PRIME-MD and/or had a score of 10 or greater on the BDI. The reasons for such low rates of depression treatment are not known, but they are likely due to the fact that depression was not routinely assessed at our tertiary care cardiology hospital, so we were likely detecting either new or previously undiagnosed cases of depression. Nonetheless, despite the apparently low rates of antidepressant prescription among patients who were depressed, our overall pattern of results suggests that antidepressant treatment may be cardio-protective in this population, and particularly among those without established CVD. They also suggest that antidepressant use, and SSRI's in particular (which were the most commonly prescribed in our population) may also reduce the risk for subsequent cardiovascular events among depressed patients, which addresses a major gap in the literature.

Taken together, our findings are consistent with those of three other studies that observed significantly reduced risks of $\mathrm{MI}$ associated with SSRI-related antidepressant use (Kimmel et al., 2011; Noordam et al., 2016; Sauer, Berlin, \& Kimmel, 2001). Our findings are also in line with trial results reported by Taylor et al., who found that antidepressant use was associated with a $43 \%$ reduction in risk of all-cause mortality and non-fatal MI among depressed post-MI patients in a secondary analysis of the ENRICHD Trial data (Taylor et al., 2005). Glassman et al. (2009) 
showed a reduced risk of cardiac events in patients treated with sertraline, however this study did not show a decreased rate of cardiac mortality between sertraline and placebo (Glassman, Bigger, \& Gaffney, 2009). Our results are inconsistent with the trial results of Zuidersma et al. (Zuidersma, Conradi, van Melle, Ormel, \& De Jonge, 2012), neither of whom found a significant association between antidepressant therapy and future risk for cardiovascular events or mortality. There are several possible explanations for these disparate results: in Zuidersma et al.'s study, patients in the "treatment" group received both pharmacological and psychotherapies, which may act on cardiovascular outcomes in different ways. Further, the trial employed a "usual care" control group, $16 \%$ of which were receiving some form of treatment for depression and may have diluted group differences. Of note, they conducted a sensitivity analyses of all those receiving some form of depression treatment (in either group) and found a significant reduction in all-cause mortality $(\mathrm{HR}=0.52,95 \% \mathrm{Cl} 0.28-0.97)$, which provides support for this hypothesis. Of note, their HR's were in the right direction (e.g., Zuidersma et al.'s mortality $\mathrm{HR}=0.74,95 \% \mathrm{Cl}: 0.41-1.33)$. Although our findings are observational, they do add to a body of literature supporting a potential protective effect of antidepressant use among patients with or at risk for CVD.

We were surprised to find that in our cohort, depression itself was not predictive of MACE when we adjusted for depression status in our analyses which demonstrated antidepressant use to be protective of MACE risk. The fact that the effect of antidepressants on risk of MACE was independent of depression status may seem counter-intuitive; however, it is likely that many of the patients taking antidepressants at baseline who were not depressed were in partial remission at the time of the baseline evaluation. This may have masked depression effects, because our baseline evaluation would have likely categorized remitted or partially remitted patients as non-depressed by failing to meet diagnostic or cut-off criteria. Since we did not collect data on psychiatric status prior to the entry into the study, we are unable to confirm this 
hypothesis. However, the fact we observed a comparable reduction in risk of MACE in our subgroup of depressed patients suggests that antidepressants are indeed cardio-protective among depressed patients.

\section{Mechanisms}

Several studies have shown that antidepressants, particularly SSRl's, are associated with reduced platelet and blood serotonin levels (Schlienger \& Meier, 2003; Wozniak, Toska, Saridi, \& Mouzas, 2011), suggesting an inhibitory effect on platelet activation which may be protective for CVD. Given the vast majority (70\%) of patients in our study were taking SSRI's provides support for this hypothesis. Further, depression is associated with an over-expression of Creactive protein and pro-inflammatory cytokines (e.g., TNF- $\alpha$, IFN-y, IL-1 and IL-6) that stimulate central serotonin (5-HT) neurotransmission (Dinan, 2008), which has been linked to both $\mathrm{Ml}$ and CVD (Wozniak et al., 2011). Thus, treatment of depression using antidepressants (and SSRI's in particular) may not only reverse or dampen the pro-inflammatory effects of depression but may also act directly on platelets, as mentioned above, to reduce CVD risk. In addition to direct pharmacological pathways, depression treatment may also improve many of the poor health behaviors that often accompany depression (e.g., increased smoking, poor dietary habits, greater physical inactivity, poor treatment adherence) (Lavoie \& Fleet, 2000). While those on antidepressants at baseline had higher rates of current smoking and comparable BMI's as those not on antidepressants, the lack of follow-up data on these variables makes it impossible to know if treatment was successful at improving these risk factors. However, the size of our observed effects is comparable with other "behavioral" predictors of improved cardiovascular risk such as physical activity (Tambalis et al., 2016), dietary habits and alcohol intake, (Yusuf et al., 2004) all of which may be influenced by changes (improvements) in mood, which provides partial support for this hypothesis. 
Finally, while unlikely, it is possible that patients who were taking antidepressants may have visited physicians more often, and as a result have received better overall health monitoring and treatment, independent of any specific effect of antidepressants. However, the fact we observed a cardio-protective effect associated with antidepressant use independent of depression status suggests that mechanisms are more likely to be pharmacological than behavioral.

\section{Limitations and strengths}

This study should be interpreted with caution in light of some limitations: First, this was not a randomized study of the effects of antidepressants on MACE, which would not have been ethical in a prospective observational study, so results should be interpreted with this in mind. Second, though we have data on what antidepressants patients were taking (primarily SSRI's), we do not have data on dose, length of treatment, or adherence (Sansone \& Sansone, 2012). Thus, any potential beneficial physiological effects associated with antidepressant use (e.g., anti-platelet or anti-inflammatory) would only be expected to occur as long as patients were taking the medication. Similarly, we have no information on psychiatric history, or whether patients were receiving other forms of depression treatment (e.g., psychotherapy) at baseline or over the follow-up. However, this level of data collection is typical of large-scale epidemiological cohort studies in this area. Second, the lack of follow-up data on changes in health behaviors (that may have been mediators of our observed depression treatment effects) is a limitation. However, this is consistent with similarly designed studies with prolonged follow-up periods from baseline (e.g., (Glassman et al., 2009; Paine, Hinderliter, et al., 2016; Perez-Cornago et al., 2016; Tambalis et al., 2016)). We were also unable to obtain a more detailed measure of ischemia quantification to include information such as Duke Score or the magnitude/location of ischemia, which could be considered a limitation. Given the prospective nature of this study and lengthy follow-up, there may be concerns that antidepressant treatments have changed. 
However, SSRI's were prescribed for the vast majority of patients in this study (70\%) and remain the most common class of pharmacotherapy for depression to this day, so we are confident our results remain highly relevant (Nassan et al., 2016). Finally, this was a primarily male (67\%) and white (99\%) sample, and may therefore not be representative of the general population. However, the proportions of men and women in this study are consistent with referral statistics to nuclear exercise stress tests (Carney et al., 2003; Yusuf et al., 2004). Despite the above limitations, this study has several notable strengths. To our knowledge, this is first study to date to examine the impact of antidepressant treatment on the prospective risk of MACE among patients with and at risk for CVD. The use of valid, reliable measures to assess depression (PRIME-MD and BDI) is another important strength. The large sample size $(n=2460)$, consecutive recruitment, and the inclusion of both men and women increases the generalizability of the findings. We also linked antidepressant use to reduced risk for MACE after adjustment for several important covariates, including CVD history and the presence of anxiety and depressive disorders, which attest to the robustness of the findings. We used multiple imputation procedures to deal with missing data that increased the reliability and representativeness of our analyses. Finally, the relatively long follow-up period (8.8 years) and the use of objective administrative database data to measure cardiovascular outcomes are other important strengths.

\section{Conclusion}

Our findings indicate a potential cardio-protective effect of antidepressants on risk for MACE over an 8.8-year follow-up among patients presenting for exercise stress tests independent of traditional risk factors including baseline depression and CVD history. However, the cardioprotective effect of antidepressants was strongest among those without a history of CVD. 
Finally, we found significantly reduced risk of MACE associated with antidepressant use in the subgroup of patients identified as depressed at baseline, which became a trend after full covariate adjustment. Though only a trend, risk reduction estimates for MACE in depressed patients (33\%) were comparable to those observed in the whole sample (30\%), suggesting antidepressant treatment may indeed reduce the risk for subsequent cardiovascular events among depressed patients, which addresses a major gap in the literature. Future studies, particularly RCT's, are encouraged to further examine the efficacy of depression treatment (pharmacological and psychotherapeutic) on cardiovascular outcomes, to further elucidate mechanisms of action.

Acknowledgements: The authors would like to thank Bernard Meloche (NMT), Lynn Jolicoeur (NMT) and Catherine Laurin, PhD for their invaluable assistance with data collection.

Financial support: Grant support from the Canadian Institutes of Health Research (CIHR: MOP 79445 and 89965, KLL \& SLB) and the Heart and Stroke Foundation of Canada, salary awards from the Fonds de la recherche du Quebec - santé (FRQS: KLL \& SLB) and CIHR (KLL \& SLB); Postdoctoral fellowships from FRQS and CIHR (MFE 146764) (both NJP) and graduate scholarship support from the Social Sciences and Humanities Research Council, CIHR and FRQS (all RP). Disclosures: The authors report there are no conflicts of interest

Author contributions: Study conception and design (KLL, SLB), acquisition of funding (KLL, SLB), data collection (KLL, SLB, RP, AA), analysis and interpretation of data (KLL, SLB, NJP), drafting of article (KLL, SLB, NJP), revising article critically for important intellectual content (KLL, NJP, SLB, RP, AA, JGD, TSC, LP), final approval of final version (KLL, NJP, SLB, RP, AA, JGD, TSC, LP). 
Table 1: Sample characteristics

\begin{tabular}{|l|l|l|l|l|l|l|}
\hline & All & $\begin{array}{l}\text { No } \\
\text { Antidepressant } \\
\text { Use (n=2195) }\end{array}$ & $\begin{array}{l}\text { Antidepressant } \\
\text { Use } \\
(\mathbf{n = 1 9 0 )}\end{array}$ & F/X2 & P & $\begin{array}{l}\text { N } \\
\text { missing }\end{array}$ \\
\hline $\begin{array}{l}\text { Demographics } \\
\text { Deme (years) }\end{array}$ & $56.8(8.52)$ & $56.9(8.56)$ & $55.7(7.96)$ & 3.71 & .05 & $0 \dagger$ \\
\hline Sex (\% Male) & $67.4(1610)$ & $69.0(1511)$ & $51.0(97)$ & 25.1 & $<.001$ & $2 \dagger$ \\
\hline BMI (kg/m $)$ & $27.5(4.79)$ & $27.6(4.75)$ & $26.7(5.21)$ & 2.11 & .15 & $1570 \dagger$ \\
\hline $\begin{array}{l}\text { Race (\% White) } \\
\text { Cohabiting (\%) }\end{array}$ & $98.7(2184)$ & $98.6(2008)$ & $100(175)$ & 2.52 & .11 & 177 \\
\hline $\begin{array}{l}\text { Education } \\
\text { (greater than 12 } \\
\text { years; \%) }\end{array}$ & $58.0(953)$ & $72.3(896)$ & $54.9(56)$ & 13.9 & $<.001$ & 1048 \\
\hline
\end{tabular}

\section{Psychiatric Status}

\begin{tabular}{|c|c|c|c|c|c|c|}
\hline $\begin{array}{l}\text { Any* Depression } \\
(\%)\end{array}$ & $38.7(921)$ & $36.7(805)$ & $61.0(116)$ & 43.57 & $<.001$ & 9 \\
\hline $\begin{array}{l}\text { PRIME-MD } \\
\text { Depressive } \\
\text { Disorder (\%) }\end{array}$ & $24.0(572)$ & $22.4(491)$ & $42.6(81)$ & 39.2 & $<.001$ & $8 \dagger$ \\
\hline $\begin{array}{l}\text { PRIME-MD Major } \\
\text { Depression (\%) }\end{array}$ & 13.8(329) & $12.5(273)$ & $29.5(56)$ & 43.28 & $<.001$ & $8 \dagger$ \\
\hline $\begin{array}{l}\text { PRIME-MD Minor } \\
\text { Depression (\%) }\end{array}$ & $9.19(219)$ & $9.22(202)$ & $8.95(17)$ & 0.02 & .90 & $8 \dagger$ \\
\hline $\begin{array}{l}\text { PRIME-MD } \\
\text { Bipolar Disorder } \\
\text { (\%) }\end{array}$ & $0.92(22)$ & $0.59(13)$ & $4.74(9)$ & 33.26 & $<.001$ & $7 \dagger$ \\
\hline $\begin{array}{l}\text { PRIME-MD } \\
\text { Dysthymia (\%) }\end{array}$ & $6.29(150)$ & $5.29(116)$ & $17.9(34)$ & 48.01 & $<.001$ & $7 \dagger$ \\
\hline $\begin{array}{l}\text { PRIME-MD } \\
\text { Anxiety Disorder } \\
(\%)\end{array}$ & $20.0(476)$ & $18.3(401)$ & $39.5(75)$ & 49.0 & $<.001$ & $10 \dagger$ \\
\hline $\begin{array}{l}\text { BDI Score } \geq 10 \\
(\%)\end{array}$ & $29.5(707)$ & $27.5(604)$ & $54.2(103)$ & 59.6 & $<.001$ & 122 \\
\hline Mean BDI Score & $8.05(7.25)$ & $7.54(6.68)$ & $13.7(10.4)$ & 129.8 & $<.001$ & $122 \dagger$ \\
\hline \multicolumn{7}{|c|}{ Clinical Characteristics } \\
\hline $\begin{array}{l}\text { Current Smoker } \\
(\%)\end{array}$ & $23.4(483)$ & $22.7(431)$ & $30.7(51)$ & 7.40 & .025 & $326 \dagger$ \\
\hline $\begin{array}{l}\text { Alcohol Heavy } \\
\text { Consumption }{ }^{\star \star} \\
(\%)\end{array}$ & $6.0(81)$ & $5.9(74)$ & $6.8(7)$ & 0.20 & .90 & $1042 \dagger$ \\
\hline CVD history (\%) & $41.4(916)$ & $41.8(851)$ & $36.6(64)$ & 1.81 & .18 & $178 \dagger$ \\
\hline Diabetes (\%) & $10.8(238)$ & $11.0(223)$ & $8.6(15)$ & 0.96 & .33 & $179 \dagger$ \\
\hline Hypertension (\%) & $43.5(961)$ & $43.9(894)$ & $38.3(67)$ & 2.09 & .15 & $179 \dagger$ \\
\hline $\begin{array}{l}\text { Hyperlipidemia } \\
(\%)\end{array}$ & $59.2(1309)$ & $60.0(1221)$ & $50.3(88)$ & 6.26 & .01 & $178 \dagger$ \\
\hline
\end{tabular}

\section{Stress Test Results}




\begin{tabular}{|c|c|c|c|c|c|c|}
\hline Ischemia (\%) & $40.8(952)$ & $41.1(881)$ & $37.6(70)$ & 0.85 & .36 & $58+$ \\
\hline $\begin{array}{l}\text { Baseline HR } \\
\text { (bpm) }\end{array}$ & $66.4(12.1)$ & $66.3(12.2)$ & $68.0(11.1)$ & 3.28 & .07 & 56 \\
\hline $\begin{array}{l}\text { Baseline SBP } \\
(\mathrm{mmHg})\end{array}$ & $135.7(20.3)$ & 136.2(20.2) & $130.6(21.1)$ & 12.8 & $<.001$ & 60 \\
\hline $\begin{array}{l}\text { Baseline DBP } \\
(\mathrm{mmHg})\end{array}$ & $85.8(11.4)$ & $86.0(11.4)$ & $83.2(11.5)$ & 11.0 & $<.001$ & 60 \\
\hline \multicolumn{7}{|l|}{ Medications } \\
\hline Ace Inhibitor (\%) & $16.9(372)$ & $16.5(336)$ & $20.6(36)$ & 1.87 & .17 & 182 \\
\hline Beta Block (\%) & $35.8(791)$ & $36.5(742)$ & $28.0(49)$ & 5.10 & .024 & 183 \\
\hline Diuretic $(\%)$ & $7.52(166)$ & 7.3(148) & $10.3(18)$ & 2.09 & .15 & 182 \\
\hline $\begin{array}{l}\text { Ca-Channel } \\
\text { Blockers (\%) }\end{array}$ & $18.5(408)$ & $18.5(377)$ & 17.7(31) & 0.07 & .79 & 181 \\
\hline $\begin{array}{l}\text { Lipid-Lowering } \\
\text { Medication (\%) }\end{array}$ & $49.3(1088)$ & $49.8(1013)$ & $42.3(74)$ & 3.67 & .06 & 181 \\
\hline $\begin{array}{l}\text { Anti-hypertension } \\
\text { Medication Use } \\
\text { (\%) }\end{array}$ & $55.3(1221)$ & $55.7(1131)$ & $51.4(90)$ & 1.17 & .28 & 182 \\
\hline $\begin{array}{l}\text { Anti-ischemic } \\
\text { Medication Use } \\
(\%)\end{array}$ & $55.3(1219)$ & $55.8(1132)$ & $49.7(87)$ & 2.41 & .12 & 185 \\
\hline Aspirin (\%) & $55.9(1167)$ & $53.7(1090)$ & $44.0(77)$ & 6.11 & .013 & 185 \\
\hline $\begin{array}{l}\text { Antidepressant } \\
\text { Use (\%) }\end{array}$ & $8.0(190)$ & - & - & - & - & $3 \dagger$ \\
\hline \multicolumn{7}{|c|}{ Cardiovascular Outcomes } \\
\hline $\begin{array}{l}\text { Mean time to } \\
\text { MACE } \\
\text { (days) }\end{array}$ & $6.84(3.09)$ & $6.80(3.11)$ & $7.20(2.87)$ & 2.93 & .09 & $1 †$ \\
\hline $\begin{array}{l}\text { Incidence of } \\
\text { MACE (\%) }\end{array}$ & $30.2(721)$ & $28.5(680)$ & $21.0(40)$ & 8.13 & .004 & $1 †$ \\
\hline
\end{tabular}

Presented as Mean (SD) or \% (n). *defined as any depressive disorder on the PRIME-MD or $\mathrm{BDI} \geq 10$ ); ${ }^{* *}$ alcohol consumption defined as greater than 3 drinks per day. $†$ Variables included in the imputation procedure 
Table 2. Unadjusted (top), adjusted for depression only (middle) and fully adjusted (bottom) association between antidepressant use and risk of MACE

\begin{tabular}{|c|c|c|c|c|}
\hline & $\beta$-estimate & Hazard Ratio & $\begin{array}{l}95 \% \text { Confidence } \\
\text { Limits }\end{array}$ & $p$-value \\
\hline \multicolumn{5}{|l|}{ Unadjusted } \\
\hline Antidepressant use & -0.429 & 0.651 & $0.474-0.896$ & .008 \\
\hline \multicolumn{5}{|c|}{ Adjusted for depression only } \\
\hline Antidepressant use & -0.435 & 0.648 & $0.470-0.892$ & .008 \\
\hline Depression* & 0.025 & 1.025 & $0.880-1.194$ & .750 \\
\hline \multicolumn{5}{|l|}{ Fully adjusted } \\
\hline Antidepressant use & -0.361 & 0.697 & $0.504-0.964$ & .029 \\
\hline Depression* & 0.033 & 1.033 & $0.875-1.221$ & .699 \\
\hline Anxiety Disorder & 0.174 & 1.189 & $0.971-1.456$ & .093 \\
\hline Sex & 0.218 & 1.244 & $1.018-1.520$ & .033 \\
\hline CVD history & 0.359 & 1.432 & $1.204-1.704$ & $<.0001$ \\
\hline Age & 0.021 & 1.021 & $1.011-1.030$ & $<.0001$ \\
\hline $\begin{array}{l}\text { Exercise-induced } \\
\text { (SPECT) myocardial } \\
\text { Ischemia }\end{array}$ & 0.602 & 1.826 & $1.548-2.153$ & $<.0001$ \\
\hline Current smoking status & 0.280 & 1.323 & $1.084-1.613$ & .006 \\
\hline Diabetes & 0.218 & 1.244 & $0.995-1.554$ & .055 \\
\hline Hypertension & 0.173 & 1.189 & $1.017-1.391$ & .030 \\
\hline Dyslipidemia & 0.101 & 1.107 & $0.927-1.320$ & .261 \\
\hline BMI & -0.011 & 0.989 & $0.955-1.025$ & .532 \\
\hline
\end{tabular}

Note: All variables coded as absent (0) or present (1), with the exception of BMI. * indicates depression diagnosis per PRIME-MD or BDI $\geq 10$ 
Table 3. Association between antidepressant use and risk of MACE, stratified by CVD status (includes index stress test result).

\begin{tabular}{|c|c|c|c|c|}
\hline Differences by CVD history & $\beta$-estimate & Hazard Ratio & 95\% Confidence Limits & $p$-value \\
\hline \multicolumn{5}{|l|}{ No CVD history } \\
\hline \multicolumn{5}{|l|}{ Unadjusted analysis } \\
\hline Antidepressant use & -0.502 & 0.605 & $0.364-1.008$ & .054 \\
\hline Depression * & 0.038 & 1.039 & $0.824-1.310$ & .749 \\
\hline \multicolumn{5}{|l|}{ Adjusted analysis } \\
\hline Antidepressant use & -0.613 & 0.542 & $0.299-0.981$ & .043 \\
\hline Depression * & 0.119 & 1.127 & $0.859-1.479$ & .390 \\
\hline \multicolumn{5}{|l|}{ CVD history } \\
\hline \multicolumn{5}{|l|}{ Unadjusted analysis } \\
\hline Antidepressant use & -0.336 & 0.715 & $0.461-1.110$ & .135 \\
\hline Depression * & 0.026 & 1.027 & $0.832-1.268$ & .806 \\
\hline \multicolumn{5}{|l|}{ Adjusted analysis } \\
\hline Antidepressant use & -0.371 & 0.690 & $0.437-1.091$ & .113 \\
\hline Depression * & -0.010 & 0.990 & $0.781-1.256$ & .936 \\
\hline
\end{tabular}

*either depression diagnosis per PRIME-MD, or BDI score $>10$. Adjusted analyses adjusted for anxiety disorder, age, exercise-induced SPECT Ischemia, current smoking status, presence of diabetes, hypertension, dyslipidemia, BMI, and sex, plus depression (shown). 
Table 4.

Adjusted association between treatment of antidepressant use in depressed patients and risk of MACE $(n=921)$

\begin{tabular}{|c|c|c|c|c|}
\hline & $\beta$-estimate & Hazard Ratio & 95\% Confidence Limits & p-value \\
\hline \multicolumn{5}{|l|}{ Unadjusted analysis } \\
\hline Antidepressant use & -0.463 & 0.629 & $0.414-0.957$ & .030 \\
\hline \multicolumn{5}{|l|}{ Adjusted analysis } \\
\hline Antidepressant use & -0.394 & 0.674 & $0.440-1.033$ & .070 \\
\hline Anxiety Disorder & 0.093 & 1.098 & $0.855-1.410$ & .465 \\
\hline Sex (male) & 0.193 & 1.213 & $0.902-1.631$ & .201 \\
\hline CVD history & 0.349 & 1.418 & $1.062-1.894$ & .018 \\
\hline Age & 0.017 & 1.017 & $1.003-1.032$ & .021 \\
\hline $\begin{array}{l}\text { Exercise-induced } \\
\text { (SPECT) myocardial } \\
\text { Ischemia }\end{array}$ & 0.679 & 1.973 & $1.516-2.566$ & $<.0001$ \\
\hline Current smoking status & 0.331 & 1.393 & $0.999-1.941$ & .050 \\
\hline Diabetes & 0.347 & 1.415 & $1.008-1.987$ & .045 \\
\hline Hypertension & 0.075 & 1.078 & $0.836-1.389$ & .564 \\
\hline Dyslipidemia & 0.032 & 1.033 & $0.779-1.370$ & .823 \\
\hline $\mathrm{BMI}$ & -0.016 & 0.985 & $0.940-1.031$ & .498 \\
\hline
\end{tabular}

Note: All variables coded as absent (0) or present (1), with the exception of BMI. Depression characterized as PRIME-MD or BDI $\geq 10$. Depression with no treatment used as reference point 


\section{Reference}

Anagnostopoulos, C, Harbinson, M, Kelion, A, Kundley, K, Loong, C Y, Notghi, A, ... Underwood, S R. (2004). Procedure guidelines for radionuclide myocardial perfusion imaging. Heart (British Cardiac Society), 90 Suppl 1, i1-10.

Anda, R., Williamson, D., Jones, D., Macera, C., Eaker, E., Glassman, A., \& Marks, J. (1993). Depressed affect, hopelessness, and the risk of ischemic heart disease in a cohort of U.S. adults. Epidemiology, 4(4), 285-294.

Ariyo, Abraham A., Haan, Mary, Tangen, Catherine M., Rutledge, John C., Cushman, Mary, Dobs, Adrian, \& Furberg, Curt D. (2000). Depressive Symptoms and Risks of Coronary Heart Disease and Mortality in Elderly Americans. Circulation, 102(15), 1773-1779.

Barefoot, J. C., Brummett, B. H., Helms, M. J., Mark, D. B., Siegler, I. C., \& Williams, R. B. (2000). Depressive symptoms and survival of patients with coronary artery disease. Psychosomatic medicine, 62(6), 790-795.

Barefoot, J. C., Helms, M. J., Mark, D. B., Blumenthal, J. A., Califf, R. M., Haney, T. L., . . . Williams, R. B. (1996). Depression and long-term mortality risk in patients with coronary artery disease. The American journal of cardiology, 78(6), 613-617.

Barzi, F., \& Woodward, M. (2004). Imputations of Missing Values in Pratice: Results from Imputations of Serum Cholesterol in 28 Cohort Studies. American Journal of Epidemiology, 160(1), 34-45.

Beck, AT, \& Steer, RA (1987). Beck Depression Inventory Manual (Vol. 1). San Antonio, TX: The Psychological Corporation, Harcourt-Brace-Jovanovich.

Beck, AT, Steer, RA, \& Garbin, MG. (1988). Psychometric properties of the Beck Depression Inventory: Twenty-five years of evaluation. Clin Psychol Reviews, 6, 77-100.

Blumenthal, James A, Lett, Heather S, Babyak, Michael A, White, William, Smith, Peter K, Mark, Daniel B, ... Newman, Mark F. (2003). Depression as a risk factor for mortality after coronary artery bypass surgery. The Lancet, 362(9384), 604-609.

Burg, Matthew M., Benedetto, M. Cristina, \& Soufer, Robert. (2003). Depressive Symptoms and Mortality Two Years After Coronary Artery Bypass Graft Surgery (CABG) in Men. Psychosomatic Medicine, 65(4), 508-510. doi: 10.1097/01.psy.0000077509.39465.79

Carney, R.M., Blumenthal, J.A., Catellier, D., Freedland, K.E., Berkman, L.F., Watkins, L.L., . . . Jaffe, A.S. (2003). Depression as a risk factor for mortality after acute myocardial infarction. The American Journal of Cardiology, 92, 1277-1281. doi: 10.1016/j.amjcard.2003.08.007

Carney, R.M., Rich, M. W., Tevelde, A., Saini, J, Clark, K, \& Jaffe, A.S. (1987). Major depressive disorder in coronary artery disease. American Journal of Cardiology, 60(16), 1273-1275.

Davidson, K. W., Bigger, J. T., Burg, M. M., Carney, R. M., Chaplin, W. F., Czajkowski, S., . . Ye, S. (2013). Centralized, stepped, patient preference-based treatment for patients with post-acute coronary syndrome depression: CODIACS vanguard randomized controlled trial. JAMA Intern Med, 173(11), 997-1004. doi: 10.1001/jamainternmed.2013.915

Dinan, TG. (2008). Inflammatory markers in depression. Curr Opin Psychiatry, 22, 32-36.

Elderon, L., Smolderen, KG. , Na, B., \& Whooley, MA. (2011). Accuracy and prognostic value of American Heart Association: recommended depression screening in patients with coronary heart disease: data from the Heart and Soul Study. Circ Cardiovasc Qual Outcomes. , 4(5), 533-540.

Frasure-Smith, N, Lesperance, F, Juneau, M, Talajic, M, \& Bourassa, M. G. (1999). Gender, depression, and one-year prognosis after myocardial infarction. Psychosomatic medicine, 61(1), 26-37. 
Frasure-Smith, N, Lesperance, F, \& Talajic, M. (1993). Depression following myocardial infarction. Impact on 6-month survival. Journal of the American Medical Association, 270(15), 1819-1825.

Frasure-Smith, N., \& Lesperance, F. (2005). Reflections on Depression as a Cardiac Risk Factor. Psychosomatic Medicine, 67(Suppl. 1), S19-25.

Frasure-Smith, N., Lesperance, F., \& Talajic, M. (1995a). Depression and 18-month prognosis after myocardial infarction. Circulation, 91(4), 999-1005.

Frasure-Smith, N., Lesperance, F., \& Talajic, M. (1995b). The impact of negative emotions on prognosis following myocardial infarction: is it more than depression? Health Psychology, 14(5), 388-398.

Glassman, Alexander H, Bigger, J Thomas, \& Gaffney, Michael. (2009). Psychiatric characteristics associated with long-term mortality among 361 patients having an acute coronary syndrome and major depression: seven-year follow-up of SADHART participants. Archives of general psychiatry, 66, 1022-1029. doi: 10.1001/archgenpsychiatry.2009.121

Harrell, F.E. (2001). Regression Modeling Strategies: With Applications to Linear Models, Logistic Regression, and Survival Analysis. New York: Springer.

Joynt, K. E., \& O'Connor, C. M. (2005). Lessons from SADHART, ENRICHD, and other trials. Psychosom Med, 67 Suppl 1, S63-66. doi: 10.1097/01.psy.0000163454.25036.fc

Katon, W. J., Lin, E. H., Von Korff, M., Ciechanowski, P., Ludman, E. J., Young, B., . . . McCulloch, D. (2010). Collaborative care for patients with depression and chronic illnesses. N Engl J Med, 363(27), 2611-2620. doi: 10.1056/NEJMoa1003955

Kimmel, SE , Schelleman, H , Berlin, JA, Oslin, DW , Weinstein, RB , Kinman, JL , . . Lewis, JD. (2011). The effect of selective serotonin re-uptake inhibitors on the risk of myocardial infarction in a cohort of patients with depression. Br J Clin Pharmacol, 72(3), 514-517.

Lane, D., Carroll, D., Ring, C., Beevers, D. G., \& Lip, G. Y. (2002). In-hospital symptoms of depression do not predict mortality 3 years after myocardial infarction. International Journal of Epidemiology, 31(6), 1179-1182.

Lavoie, K. L., \& Fleet, R. P. (2000). The impact of depression on the course and outcome of coronary artery disease: review for cardiologists. Canadian Journal of Cardiology, 16(5), 653-662.

Lesperance, F., Frasure-Smith, N., Talajic, M., \& Bourassa, M. G. (2002). Five-year risk of cardiac mortality in relation to initial severity and one-year changes in depression symptoms after myocardial infarction. Circulation, 105(9), 1049-1053.

Lichtman, JH, Froelicher ES, Blumenthal JA, Carney RM, Doering LV, Frasure-Smith N, ... Nursing., American Heart Association Statistics Committee of the Council on Epidemiology and Prevention and the Council on Cardiovascular and Stroke. (2014). Depression as a risk factor for poor prognosis among patients with acute coronary syndrome: systematic review and recommendations: a scientific statement from the American Heart Association. Circulation., 129, 1350-1369.

Luepker, R.V., Evans, A., McKeigue, P., \& Reddy, K.S. (2004). Cardiovascular survey methods (3rd edition ed.). Geneva: World Health Organisation.

Moullec, G, Plourde, A , Lavoie, KL , \& Bacon, SL. (2015). Beck Depression Inventory II: determination and comparison of its diagnostic accuracy in subgroups of individuals suspected of coronary artery disease (CAD). Eur J Prev Cardiol 22(5), 665-672.

Nassan, M., Nicholson, W. T., Elliott, M. A., Rohrer Vitek, C. R., Black, J. L., \& Frye, M. A. (2016). Pharmacokinetic Pharmacogenetic Prescribing Guidelines for Antidepressants: A Template for Psychiatric Precision Medicine. Mayo Clin Proc, 91(7), 897-907. doi: 10.1016/j.mayocp.2016.02.023 
Noordam, R, Aarts, N, Leening, MJ, Tiemeier, H, Franco, OH, Hofman, A, . . Visser, LE. (2016). Use of antidepressants and the risk of myocardial infarction in middle-aged and older adults: a matched case-control study. Eur J Clin Pharmacol, 72(2), 211-218.

Paine, Nicola J., Bacon, Simon L., Pelletier, Roxanne, Arsenault, André, Diodati, Jean G., \& Lavoie, Kim L. (2016). Do Women With Anxiety or Depression Have Higher Rates of Myocardial Ischemia During Exercise Testing Than Men? Circulation: Cardiovascular Quality and Outcomes, 9(2 suppl 1), S53-S61. doi: 10.1161/circoutcomes.115.002491

Paine, Nicola J., Hinderliter, Alan L., Blumenthal, James A., Adams Jr, Kirkwood F., Sueta, Carla A., Chang, Patricia P., ... Sherwood, Andrew. (2016). Reactive hyperemia is associated with adverse clinical outcomes in heart failure. American Heart Journal, 178, 108-114. doi: http://dx.doi.org/10.1016/i.ahi.2016.05.008

Pelletier, R., Bacon, S. L., Arsenault, A., Dupuis, J., Laurin, C., Blais, L., \& Lavoie, K. L. (2015). Relative associations between depression and anxiety on adverse cardiovascular events: does a history of coronary artery disease matter? A prospective observational study. BMJ Open, 5(12), e006582. doi: 10.1136/bmjopen-2014-006582

Perez-Cornago, A., Sanchez-Villegas, A., Bes-Rastrollo, M., Gea, A., Molero, P., LahortigaRamos, F., \& Martinez-Gonzalez, M. A. (2016). Relationship between adherence to Dietary Approaches to Stop Hypertension (DASH) diet indices and incidence of depression during up to 8 years of follow-up. Public Health Nutr, 1-10. doi: $10.1017 / \mathrm{s} 1368980016001531$

Rosengren, A., Hawken, S., Ounpuu, S., Sliwa, K., Zubaid, M., Almahmeed, W. A., . . Yusuf, S. (2004). Association of psychosocial risk factors with risk of acute myocardial infarction in 11119 cases and 13648 controls from 52 countries (the INTERHEART study): casecontrol study. Lancet, 364(9438), 953-962.

Rubin, D.B. (1987). Multiple Imputation for Nonresponse in Surveys. New York: Wiley.

Sansone, R. A., \& Sansone, L. A. (2012). Antidepressant adherence: are patients taking their medications? Innov Clin Neurosci, 9(5-6), 41-46.

Sauer, Heinrich., Berlin, Jesse A., \& Kimmel, S.E. (2001). Selective serotonin reuptake inhibitors and myocardial infarction. Circulation, 108 (1), 32-36.

Schlienger, RG., \& Meier, CR. (2003). Effect of selective serotonin reuptake inhibitors on platelet activation: Can they prevent myocardial infarction? Am J Cardiovascular Drugs, 3(3), 149-162.

Spitzer, R.L., Kroenke, K., \& Williams, J.B. (1999). Validation and utility of a self-report version of PRIME-MD: the PHQ primary care study. Primary Care Evaluation of Mental Disorders. Patient Health Questionnaire. Jama, 282(18), 1737-1744.

Spitzer, R.L., Williams, J.B., Kroenke, K., Linzer, M., deGruy, F.V., Hahn, S.R., . . Johnson, J.G. (1994). Utility of a new procedure for diagnosing mental disorders in primary care. The PRIME-MD 1000 study. JAMA, 272, 1749-1756.

Steeds, Richard, Bickerton, D, Smith, MJ, \& Muthusamy, R. (2004). Assessment of depression following acute myocardial infarction using the Beck Depression Inventory. Heart, 90, 217-218.

Tambalis, K. D., Panagiotakos, D. B., Georgousopoulou, E. N., Mellor, D. D., Chrysohoou, C., Kouli, G. M., . . . Pitsavos, C. (2016). Impact of physical activity category on incidence of cardiovascular disease: Results from the 10-year follow-up of the ATTICA Study (20022012). Prev Med, 93, 27-32. doi: 10.1016/j.ypmed.2016.09.023

Taylor, CB , Youngblood, ME , Catellier, D , Veith, RC , Carney, RM , Burg, MM, ... Investigators., ENRICHD. (2005). Effects of antidepressant medication on morbidity and mortality in depressed patients after myocardial infarction. Arch Gen Psychiatry, 62(7), 792-798. 
Thombs, BD, de Jonge, P, Coyne, JC, Whooley, MA, Frasure-Smith, N, Mitchell, AJ , .. . Ziegelstein, RC. (2008). Depression screening and patient outcomes in cardiovascular care: a systematic review. JAMA. , 300, 2161-2171.

Thombs, BD, Roseman, M, Coyne, JC, de Jonge, P, Delisle, VC, Arthurs, E, ... Zeigelstein, RC. (2013). Does evidence support the American Heart Association's recommendation to screen for depression in cardiovascular care? Plos One, 8, e52654.

Wozniak, G., Toska, A., Saridi, M., \& Mouzas, O. (2011). Serontonin reuptake inhibitor antidepresssants (SSRI's) against atherosclerosis. Med Science Monitor, 17(9), RA205214.

Yusuf, Salim, Hawken, Steven, Ounpuu, Stephanie, Dans, Tony, Avezum, Alvaro, Lanas, Fernando, ... . Lisheng, Liu. (2004). Effect of potentially modifiable risk factors associated with myocardial infarction in 52 countries (the INTERHEART study): casecontrol study. Lancet, 364(9438), 937-952. doi: 10.1016/S0140-6736(04)17018-9

Zuidersma, M., Conradi, H.J., van Melle, J.P., Ormel, Johan, \& De Jonge, P. (2012). Depression treatment after myocardial infarction and long term risk of subsequent cardiovascular events and mortality: A randomized controlled trial. Journal of Psychosomatic Research, 74, 25-30. 
Figure 1. Kaplan Meier survival curve for the use of anti-depressants on risk of MACE, for the whole sample. Solid line presents no anti-depressant use; dashed line indicates anti-depressant use

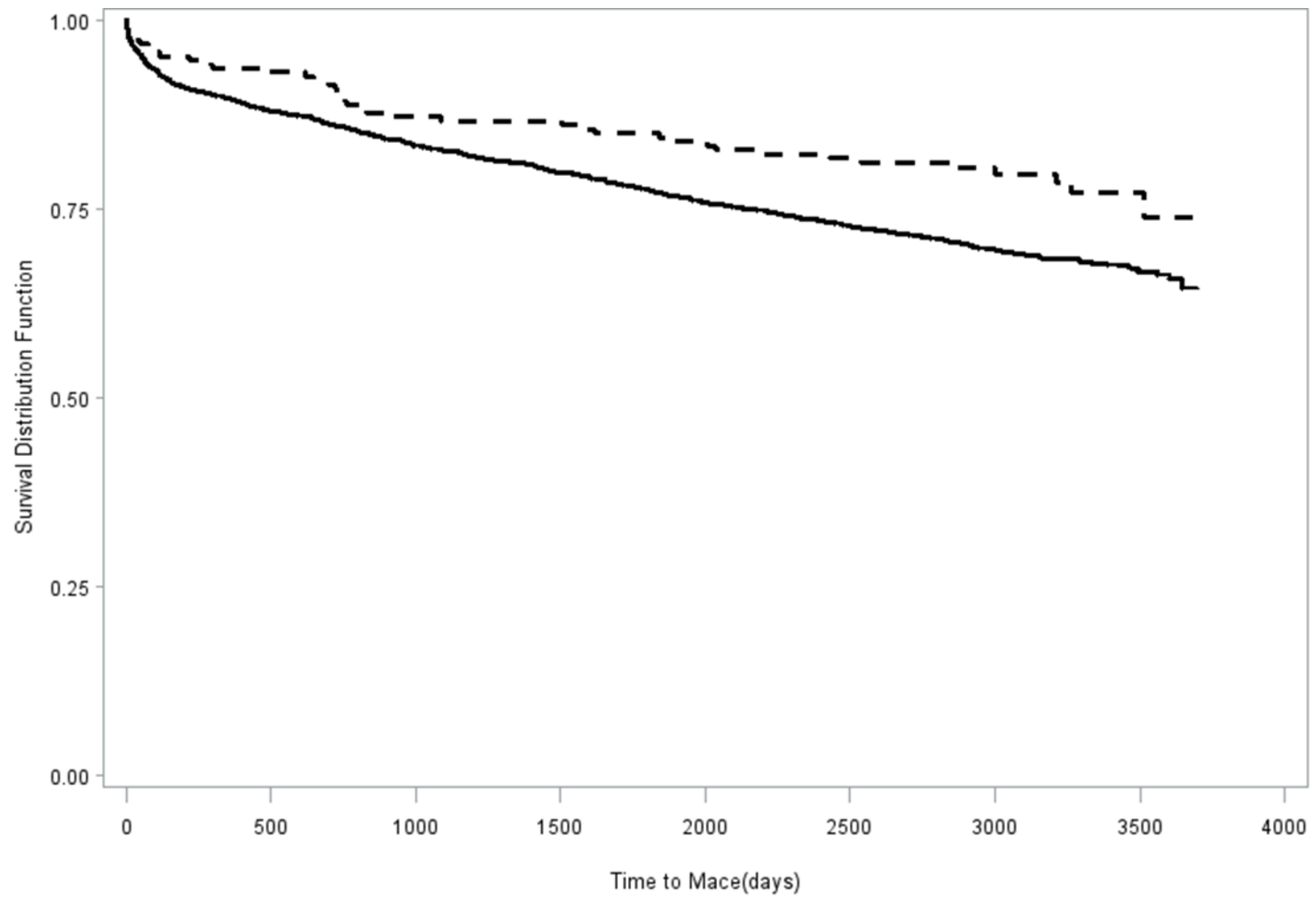


Figure 2. Kaplan Meier survival curve for the use of anti-depressants on risk of MACE, for patients without CAD history (top) and CAD history (bottom). Solid line presents no anti-depressant use; dashed line indicates anti-depressant use
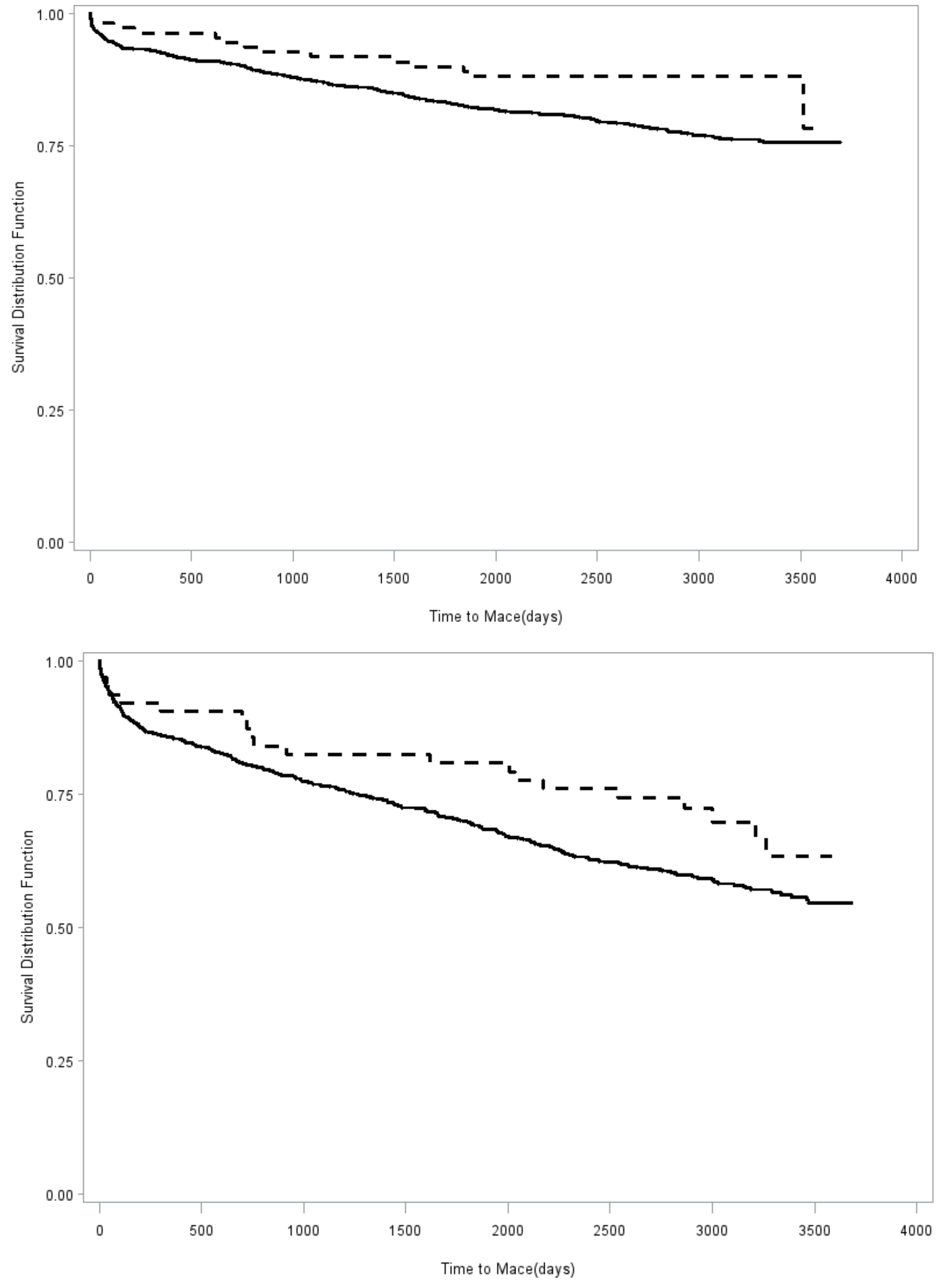